Review Article

https://doi.org/10.20546/ijcmas.2018.708.159

\title{
Review on Avian Electrocardiogram
}

\author{
S. Yogeshpriya ${ }^{1 *}$, P. Selvaraj ${ }^{1}$, P.K. Ramkumar ${ }^{2}$, M. Veeraselvam ${ }^{1}$, M. Saravanan², \\ M. Venkatesan ${ }^{1}$ and K. Jayalakshmi ${ }^{1}$
}

${ }^{1}$ Department of Veterinary Medicine, ${ }^{2}$ Veterinary Clinical Complex, Veterinary College and Research Institute, Tamilnadu Veterinary and Animal Sciences University,

Orathanadu-614625, India

*Corresponding author

\section{A B S T R A C T}

\begin{tabular}{|c|}
\hline Keywords \\
\hline $\begin{array}{l}\text { Electrocardiogram; } \\
\text { ECG, } \\
\text { Bird; }\end{array}$ \\
\hline Article Info \\
\hline $\begin{array}{l}\text { Accepted: } \\
\text { 10 July } 2018 \\
\text { Available Online: } \\
10 \text { August } 2018\end{array}$ \\
\hline
\end{tabular}

\section{Introduction}

The avian cardiovascular system is designed to match the high metabolic demand of birds and it comprises of a large heart, high heart rate, high cardiac output, and high blood pressure. These unique high-performance features of the avian heart enable birds to fly, run, or dive. However, pet birds often are compromised in their cardiovascular capabilities by restricted exercise, poor diet, and abnormal climate. These factors may predispose for cardiovascular disease in captive birds (Martine, 2005). Many times backyard poultry companions are presented for evaluation for poor performance.

The electrocardiogram (ECG), a graphic representation of the electrical activity of the heart is a useful diagnostic tool in evaluation of cardiovascular system. It is also a good tool for clinical assessment of patients subsequent to severe trauma, electrocution, and for the clinical diagnosis and monitoring of several cardiac and whole body abnormalities including arrhythmias, conduction disorders and electrolyte imbalances (Hassanpour et al., 2010; Cushing et al., 2013). Despite its great 
clinical applicability, avian practitioners have given relatively little attention to electrocardiography probably because of scarcity of reference values in companion, zoo and wild birds (Hassanpour et al., 2014). Although the avian cardiovascular system shares many similarities with those of mammals, several unique and specific details exist. The mass of the avian heart is nearly twice as large as that of a mammal of comparable size and it is designed to meet high-performance demands (KrautwaldJunghanns et al., 2004). Stroke volume in avians species is bigger and they have cardiac output is higher than those of mammals.

Consequently, avian heart rate can be as high as 1000 beats/min depending on the species (Pees and Krautwald-Junghanns, 2009) allowing for high demands of oxygen during activities like flight, running or diving (de Wit and Schoemaker, 2005). The cardiac electrical conduction system of birds is similar to that of mammals consisting of a sinoatrial node, an atrioventricular node, and Purkinje fibers. The primary pacemaker is the sinoatrial node which conducts the electrical impulse to the atrioventricular node and by way of the atrioventricular bundle to the ventricles. There is an additional atrioventricular ring which functions to make fast depolarization of the ventricles (Sturkie and Whittow, 2000).

The avian ECG differs from those of humans and some other mammals because the depolarization wave of avian ventricle moves from the epicardium to the endocardium (Lumeij and Ritchie, 1994). Changes in the avian ECG have been reported in some infectious diseases such as Escherichia coli, Newcastle and influenza virus infections as well non-infectious conditions such as thiamine deficiency and hyperkalemia (Espino et al., 2001). The physiological parameters of birds can be affected by environmental factors such as ambient temperature and relative humidity (Donkoh, 1989).
One of the most useful tool for evaluation of cardiac function of animals in both infectious and non-infectious condition is Electrocardiography (ECG) (Hassanpour et al., 2009). In India, avian cardiology is one of the previously neglected and presently developing areas of clinical veterinary medicine. Avian ECG differs somewhat from its mammalian counterpart in that the RS wave is inverted in most species as a norm (Machida and Aohagi, 2001). Avian electrocardiogram (ECG) was first recorded in 1909, and it showed that the avian ECG, unlike the human ECG, had a deep $S$ wave but no $\mathrm{R}$ wave (Buchanan, 1909). A method for recording ECGs of chickens with standard bipolar limb leads was reported in 1949. Thereafter, additional electrocardiographic studies were undertaken for several avian species, including chicken, turkey, quail, duck, pigeon, and parrot.

To evaluate morphologic features of the avian ECG, it is important to have an ECG machine that has a speed of $100 \mathrm{~mm} / \mathrm{s}$ or greater (may need $200 \mathrm{~mm} / \mathrm{s}$ in very small patients). At slower speeds the ECG wave forms are too close together to interpret but the tracing may be useful as a monitoring device during anesthesia and may be used to detect arrhythmias. The ECG demonstrates the summed electrical activity of the heart. In birds, the mean electrical axis is negative (and thus the QRS wave is inverted in lead II); however, in many other respects the avian ECG is similar to mammals. The standard bipolar limb lead II is commonly used to evaluate ECG wave forms in birds (Fig. 1, 2 and 3). The sensitivity of the ECG should be adjusted to produce wave forms that fit fully within the tracing paper, yet do not exceed the edge.

\section{Anatomy and physiology of avian heart}

The avian heart differs from mammalian heart in that it is cone-shaped and it has a thin right 
ventricle (RV) and thick left ventricle (LV) wall (1:4). A muscular flap rather than mammalian type valves separates the right atrium and ventricle.

The muscle flap is a continuation of muscle from the right ventricle wall. Hypertrophy of the RV wall results in thickening of the valve and leads to valvular insufficiency. Other valves are similar to mammalian heart. A cartilaginous plaque is found in the wall of the aorta where major vessels leave the heart

Avian hearts also tend to pump more blood per unit time than mammalian hearts. In other words, cardiac output (amount of blood pumped per minute) for birds is typically greater than that for mammals of the same body mass. Cardiac output is influenced by both heart rate (beats per minute) and stroke volume (blood pumped with each beat). 'Active' birds increase cardiac output primarily by increasing heart rate.

\section{Electrical activity in the avian heart}

The avian ECG also starts with a $\mathrm{P}$ wave, but is in some groups of birds it is followed by a slight depression of the initial part of the PR interval. This depression, referred to as the Ta wave, represents atrial repolarization and appears to be a physiologic phenomenon in pigeons and some gallinaceous and psittacine birds. The second difference is the form of the QRS complex, which should more accurately be described as a rS complex.

This is due to the fact that the ventricular depolarization in the avian heart starts subepicardially spreading via the myocardium to the endocardial surface, in contrast to the mammalian heart, where it spreads from the endocardial side to the epicardial side. The ST segment is rather short or absent. When present, as commonly found in healthy pigeons and psittacines species, it is often elevated or shows ST-slurring (S wave directly merging into the $\mathrm{T}$ wave). In mammals, an elevated ST segment or STslurring is associated with cardiac disease in and it is not so in pigeons or psittacine birds. The $\mathrm{T}$ wave is opposite to the direction of the ventricular complex and always positive in lead II. The P-on-T phenomenon (the $\mathrm{P}$ wave is superimposed on the $T$ wave) is a normal finding.

\section{Indications of Avian ECG Recording}

The ECG has been used for documenting a number of abnormalities in canine cardiology including:

Cardiac chamber enlargement

Pericardial/pleural effusion

Hypoxia, acid- base or electrolyte disturbances (mainly changes in potassium concentrations)

Monitoring the development of cardiac disease

Diagnosing cardiac arrhythmias and conduction disturbances

Evaluating and monitoring the effects of cardioactive drugs

Monitoring cardiac function before, during and after surgical procedures

Assessing the heart rate when the femoral pulse is not easily appreciable (i.e, small animals, hypotensive shock) or when counting heart beats is made difficult by tachycardia or an abnormal rhythm 


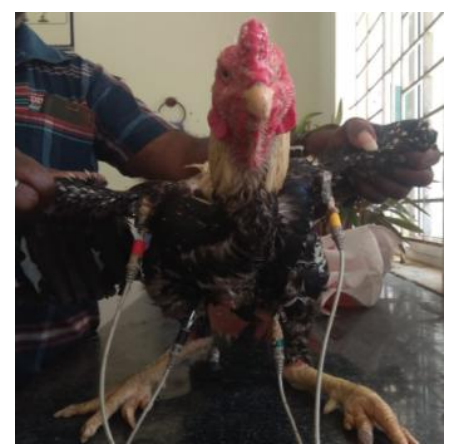

Fig.1 Recording of ECG in a Backyard bird

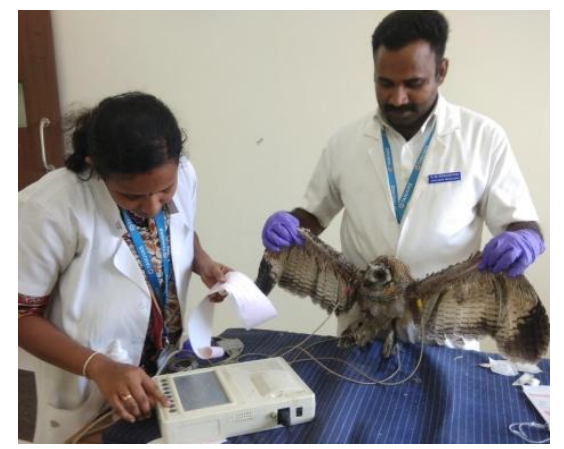

Fig.2 Recording of ECG in a Wood Owl

Schematic representation of a normal Lead II Electrocardiogram of a parrot (Paper speed 200mm/s;1 cm=1Mv)

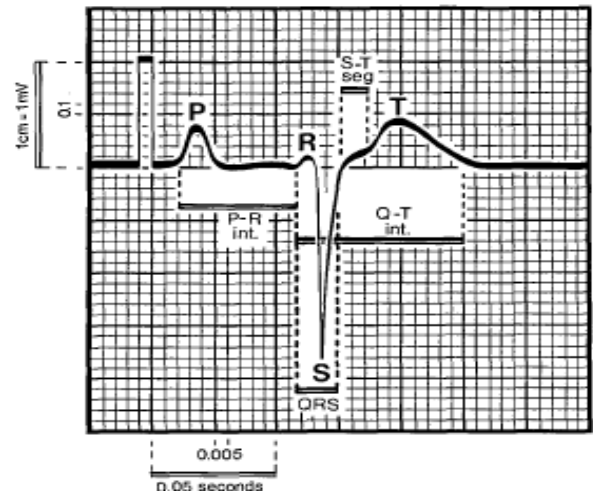

Fig.2 Electrocardiography in apparently healthy domestic poultry 1 (Lead II). Paper speed 50 $\mathrm{mm} / \mathrm{s} ; 1 \mathrm{~cm}=1 \mathrm{mV}$

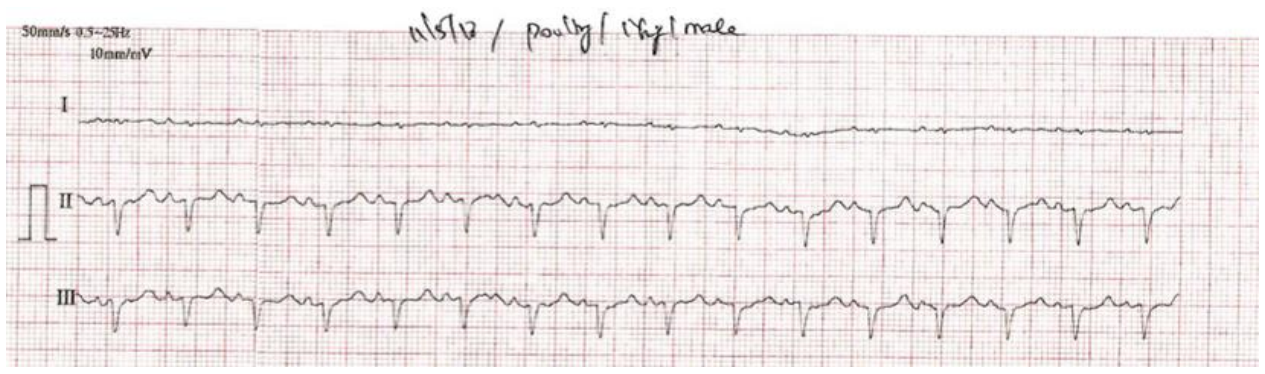

Fig.3 Electrocardiography in apparently healthy domestic poultry 2 (Lead II). Paper speed $50 \mathrm{~mm} / \mathrm{s} ; 1 \mathrm{~cm}=1 \mathrm{mV}$

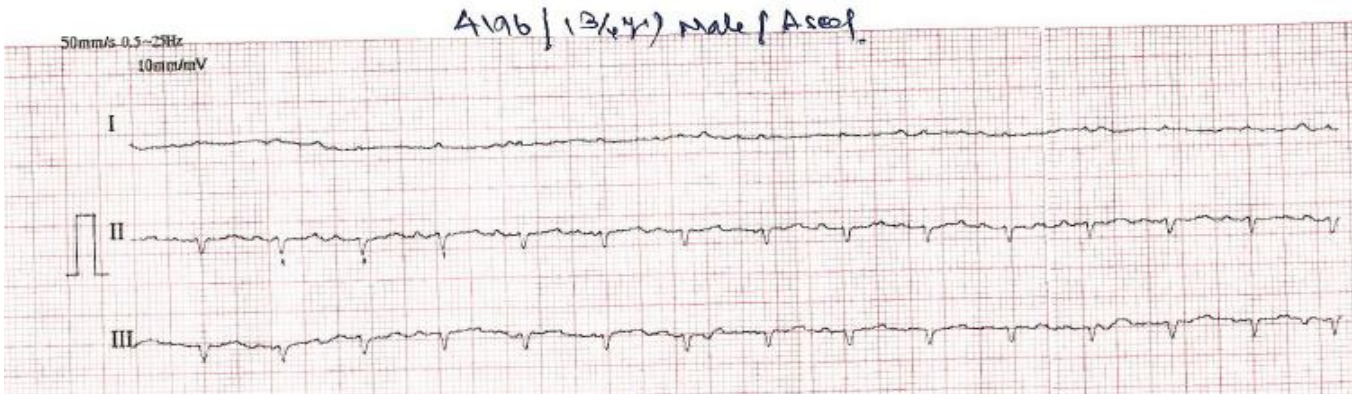


Fig.4 Electrocardiography in apparently healthy Turkey (Lead II). Paper speed $50 \mathrm{~mm} / \mathrm{s} ; 1 \mathrm{~cm}=1 \mathrm{mV}$

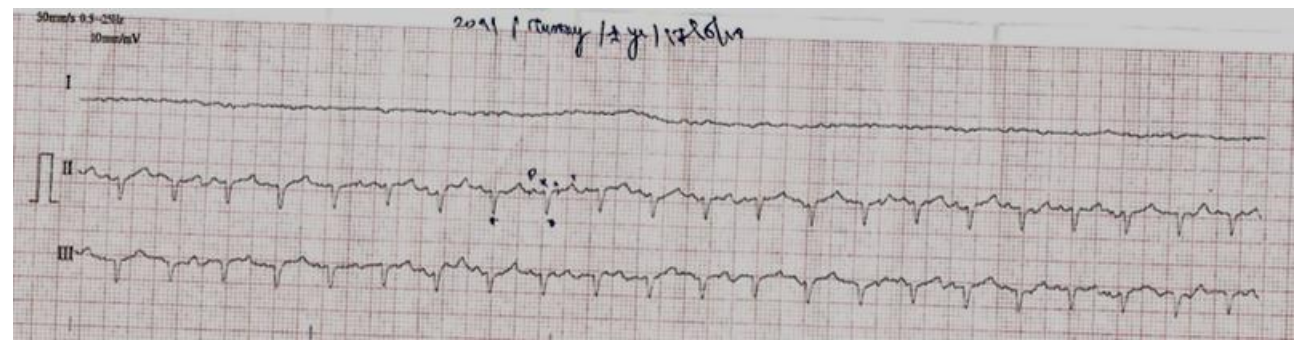

Table.1 The values for intervals, durations and amplitudes of the waves and heart rate

\begin{tabular}{|l|}
\hline Variables \\
\hline Heart rate (beats/min) \\
\hline P(s) \\
\hline P(mV) \\
\hline PR(s) \\
\hline QRS-complex (s) \\
\hline R(mV) \\
\hline QT(s) \\
\hline ST $(s)$ \\
\hline$T(s)$ \\
\hline$T(m V)$ \\
\hline
\end{tabular}

\begin{tabular}{|l|l|l|}
\hline Domestic poultry 1 & Domestic poultry 2 & Turkey \\
\hline 250 & 250 & 272 \\
\hline 0.02 & 0.02 & 0.02 \\
\hline 0.1 & 0.1 & 0.1 \\
\hline 0.1 & 0.1 & 0.08 \\
\hline 0.04 & 0.02 & 0.04 \\
\hline 0.6 & 0.3 & 0.5 \\
\hline 0.14 & 0.12 & 0.14 \\
\hline 0.1 & 0.1 & 0.08 \\
\hline 0.06 & 0.02 & 0.04 \\
\hline 0.2 & 0.1 & 0.1
\end{tabular}

\section{Surface electrode placement}

It is easiest to perform an ECG on a bird in dorsal recumbency, but right lateral or ventral recumbency is equally effective. The electrodes are attached to the Right wing (RA), the Left wing (LA) and the left limb (LL). The right hind limb (RL) of the bird is connected to the ground electrode (Oglesbee et al., 2001). At present, for regular electrocardiography analysis of birds, ECG machine with a speed of $50 \mathrm{~mm} / \mathrm{sec}$ was used in our study (unpublished). If the speed of the machine is lower, the ECG waveforms are too close together and it is difficult to analysis. While recording ECG, if needle electrodes are used, then it should be placed subcutaneously, onto which the alligator clips are attached. In few birds, directly alligator clips alone can be attached. To prevent artifact and skin damage, application of gel is recommended while recording ECG. Anaesthesia is not recommended while tracing the electrocardiography unless required. Lead I in evaluated birds is nearly isoelectric. The lead II electrocardiogram is shown in Fig. 3-5. All measurements are made on the Lead II rhythm.

For these birds, no real reference values for their ECG values are available. It is possible, however, to determine the heart rate. Standardized reference values still have to be established. The values for intervals, durations and amplitudes of the waves and heart rate are presented in Table 1.

Electrocardiography is a useful diagnostic tool in birds. In birds, severe cardiac histopathology is not always reflected in ECG abnormalities, and that severe ECG 
abnormalities have been reported in individuals with a normal cardiac histopathology. While interpretation of an ECG, one should always consider history, clinical findings and laboratory results before diagnosis.

\section{Conflict of interest}

The author declares no conflict of interest

\section{References}

Buchanan F, 1909. The frequency of the heart beat and the form of the electrocardiogram in birds. J Physiol 38: 62-66.

Cushing, A., Linney, C., McClean, M., Stanford, M., \& Rishniw, M. (2013): The electrocardiogram of anesthetized captive adult emus (Dromaius novaehollandiae). Journal of Veterinary Cardiology, 15(1), 51-56

De Wit Martine, Nico J. Schoemaker Clinical Approach to Avian Cardiac Disease. Topics in Medicine and Surgery. Seminars in Avian and Exotic Pet Medicine, Vol 14, No 1, 2005: pp 6-13

Donkoh, A., (1989): Ambient temperature: a factor affecting performance and physiological response of broiler chickens. International Journal of Biometeorology, 33(4), pp. 259-265

Espino, L., Suárez, M. L., López-Beceiro, A., \& Santamarina, G. (2001): Electrocardiogram reference values for the buzzard in Spain. Journal of wildlife diseases, 37(4), 680-685.

Hassanpour et al., 2010; Hassanpour, H., Moghaddam, A. and Zarei, H., (2009): Effect of citric acid on electrocardiographic parameters of broiler chickens with pulmonary hypertension. Acta Veterinaria Hungarica, 57(2), pp. 229-238
Hassanpour, H., Moghaddam, A. and Zarei, H., (2009): Effect of citric acid on electrocardiographic parameters of broiler chickens with pulmonary hypertension. Acta Veterinaria Hungarica, 57(2), pp.229-238

Hassanpour, H., Shamsabadi, M. G., Dehkordi, I. N., and Dehkordi, M. M. (2014): Normal electrocardiogram of the laughing dove (Spilopelia senegalensis) Journal of Zoo and Wildlife Medicine, 45(1), 41-46.

Krautwald-Junghanns ME, Straub J. Avian cardiology: part I. In: Association of Avian Veterinarians Annual Conference Proceedings, Orlando; 2001. Pp. 32330.

Lumeij J, Ritchie B. Cardiology. In: Ritchie B, Harrison G, Harrison L, editors. Avian medicine: principles and applications. Lake Worth (FL): Wingers Publishing; 1994. p. 695-722.

Lumeij J, Ritchie B. Cardiology. In: Ritchie B, Harrison G, Harrison L, editors. Avian medicine: principles and applications. Lake Worth (FL): Wingers Publishing; 1994. p. 695-722.

Machida N, Aohagi Y (2001): Electrocardiography, heart rates and heart weights of free-living birds. J Zoo Wildl Med. 2001; 32(1): 47-54.

Machida N, Aohagi Y. Electrocardiography, heart rates, and heart weights of freeliving birds. J Zoo Wildl Med 2001; 32(1):47-54.

Martine de Wit (2005). Clinical Approach to Avian Cardiac Disease, Seminars in Avian and Exotic Pet Medicine, 14 (1): 2005: 6-13

Oglesbee B, Hamlin R, Klingaman H, et al., Electrocardiographic reference values for Macaws (Ara species) and Cockatoos (Cacatua species). J Avian Med Surg 2001; 15(1): 17-22.

Pees M, Straub J, Krautwald-Junghanns ME. Pericardial effusion in birds: 
demonstration of clinical cases. In: Association of Avian Veterinarians Annual Conference Proceedings, Sturkie, P. D. and G. C. Whittow. (2000). Sturkie's Avian Physiology. Academic Portland; 2000. p. 189-91

\section{How to cite this article:}

Yogeshpriya, S., P. Selvaraj, P. K. Ramkumar, M. Veeraselvam, M. Saravanan, M. Venkatesan and Jayalakshmi, K. 2018. Review on Avian Electrocardiogram. Int.J.Curr.Microbiol.App.Sci. 7(08): 1389-1395. doi: https://doi.org/10.20546/ijcmas.2018.708.159 